\title{
BJ

THE IMPACT OF STRATEGIC PLANNING ON INSTITUTIONAL INTEGRATION TOWARD PATRIMONIAL AND PERIMETER SECURITY PLANNING OF THE 2016 OLYMPICS GAMES

Andre Henrique Cunha andrehdcunha@hotmail.com Federal University of Santa Catarina

- UFSC, Florianópolis, Santa

Catarina, Brazil

\section{Nazareno Marcineiro} nazarenomarcineiro@gmail.com Federal University of Santa Catarina

- UFSC, Florianópolis, Santa

Catarina, Brazil

\section{Helio Aisenberg Ferenhof} helio@igci.com.br

Federal University of Santa Catarina

- UFSC, Florianópolis, Santa

Catarina, Brazil

Fernando Antônio Forcellini forcellini@gmail.com

Federal University of Santa Catarina

- UFSC, Florianópolis, Santa

Catarina, Brazi

\begin{abstract}
After the legacy of September 11, 2001, and subsequent terrorist attacks during sports events, such as the London (2005) bombings, is evidenced in the increased security measures put in place at major sports events. Heightened attention to safety management and public concern about possible threats and perception of risk has now become a fundamental component of the planning and risk management strategies for sports events. To deal with this issue, this study aims to systemize and develop the strategic planning process for security operations of the gaming facilities and to the public in general within the games perimeter, during the 2016 Olympics in Rio de Janeiro, Brazil. We took basis on MCDA-C (Multi-Criteria Methodology Decision Support - Constructivist), to develop a system capable of promoting the institutional integration of Brazilian security forces to ensure the public and playing field's safety, as well as the games perimeter and public and private property used for the 2016 Olympic Games. The system starts with a business environment analysis, and service requirements analyzes, and, with the MCDA-C's assistance, a relevance matrix was constructed, and, from it, resources and operations plans were set. Finally, the Olympics Games Rio 2016 strategic security operations plan results were discussed.
\end{abstract}

Keywords: Perimeter and Property Security; National Force; Olympics; Strategic Security Planning; Police Science. 
Brazilian Journal of Operations \& Production Management

Volume 15, Número 2, 2018, pp. 285-293

DOI: 10.14488/BJOPM.2018.v15.n2.a10

\section{INTRODUCTION}

This article aims to discuss some aspects related to the concerns and solutions of the Brazilian National Security Force work, for the realization of a mega sports event that occurred in 2016 (Olympic Games). Therefore, some discussions dealing with the plans and security activities in mega events, followed by an analysis of the strategic security planning for the Olympics in 2016 will be presented.

In the case of this mega event, anywhere in the world, investments and strategies have been planned in advance and well above the level of detail, such as what was seen in the 2007 Pan American Games, mainly because they reach great importance and visibility (Cardoso, 2010).

It should be highlighted that three types of risk are commonly identified, each of them representing different types of "legacy": political violence or terrorism; violence between/of spectators and, urban violence or local crime (Giulianotti; Klauser, 2009). In terms of legacy, this work shows the strategic plan development of the public security and the playing field, regarding the perimeter dimension, property and electronic security of the 2016 Olympics Games.

Regarding security, another performance model is needed. A model that is characterized by the collective action, the information circulation, and methodological modernization. Some factors are decisive for the creation of a new model. A paradigmatic example can be taken from field work by Cardoso (2010): in 2008 he followed the day by day working surveillance video system service of the state of Rio de Janeiro. As result, some operational difficulties were identified and highlighted: those related to the lack of integration (or fragmentation) between the different institutions and/ or institutional sectors, which was part of the same system, even if they are located in the same room.

Moreover, regarding the lack of integration, it is emphasized that, according to Qazi et al. (2016), it is not only important to evaluate the complexity involved in each part of the project of the organizations, but also to visualize the complex interaction between project complexity and complexity induced risks in order to prioritize critical risks and select optimal risk mitigation strategies.

Taking these factors into consideration, the Federal Government of Brazil has decided that the physical security of the Olympics facility would have a lower cost if done by a public organization, compared to the price charged by private security companies. Therefore, the mission was assigned to the Department of National Public Security Force (DFNSP) by the Official Letter 66/2015 / GAB-SESGE / SESGE-MJ.
The Official Letter 66/2015 describes the DFNSP mission: (i) Perimeter Security, Property and Electronic security; (li) Public and Field Safety; (lii) Safety Fencing and; (Iv) Mag \& Bag Security. These activities would be held in the city of Rio de Janeiro, in four different places, called Olympic Regions, located in Barra, Copacabana, Deodoro and Maracanã. In these four areas, the security activities on those items would be held in 49 facilities in the Olympics and 38 facilities in the Paralympics, with the first 32 competition venues, 9 facilities with no competition, such as accommodation and others, and 8 training facilities. The Paralympics Games would take place in 22 competition venues, 7 non-competition venues and 4 training facilities.

The DFNSP mission was expanded in so far as new security demands were emerging as a result of the development of the Integrated Tactical Plan for Public Safety and Civil Defense for the Rio 2016 Games, which was held by representatives of all security and defense bodies under the coordination of the Major Events Secretariat (SESGE), of the Ministry of Justice. This event added new assignments to the National Force to: (i) the convoy of athletes during the opening and closing ceremonies of the games; (ii) Olympic and Paralympic torch security and escort, and; (iii) Olympics and Paralympics medals security and protection.

Thus, it was understood that the biggest challenge that must be overcome is to reach the police forces integration within the different institutions that compose the DFNSP. These institutions must share information and work together in a coordinated manner.

It could be said that the Brazilian public security fits on what Duarte and Firmino (2010, p. 104) calls recombinant architecture, a term used for "strengthening the idea of an existing space (conceptually) diluted by new paradigms and recombined with new elements". This is evident if it is considered that the main pillar of this institutional integration movement is sustained through the modernization of the template-driven security forces. Therefore, the challenge to be considered in this work should be emphasized, in order to prepare the strategic planning for the realization of the 2016 Olympics and Paralympics Games.

\section{THEORETICAL BACK GROUND}

The Strategic Plan defines which action plan the organization will adopt to be ahead of the competitors and achieve the company objectives. The plan may be of a long, medium or short-term. In planning, the past and present events should always be taken into account. When developing a strategic plan, the organization builds conditions and means to act on the internal and external variables with major and minor difficulties such as strengths and weaknesses, threats 
and opportunities. The companies that formulate such plan will not be surprised when such variables stand out because, somehow, those companies have already expected that such events could occur within the proposed planning (Oliveira, 2010).

According to Tavares (2008), Strategic Planning is the process designed to understand the environment in order to formulate and implement strategies to seize opportunities and neutralize threats. Strategic planning provides, from a systemic perspective, a greater interaction between the organization and the environment in which it operates. In this context, it encourages a more purposeful pursuit of the future as well as it provides a better development of organizational models that are suited to environmental demands, integrating people, skills and resources.

Strategic management is intended to ensure that the organization can interact with its operational environment in an appropriate manner. Environments change rapidly and steadily, thus organizations must transform themselves within a "right manner" in order to ensure that the proposed targets will be reached (Araujo, 2010).

The strategic management cycle closes in strategic control stage. Therefore, it is necessary clarity in terms of the effects of the actions expected, in order to compare it with expected standards, usually numerical, although qualitative assessments are not discarded or depreciated. If there is a discrepancy between the results obtained in strategic management and expected standards, formulated action plans are fixed. It can be difficult to interpret numerical indicators; therefore, numbers compositions must sometimes be used to sort a situation. Moreover, the strategic control can refeed the formulated action plans (Oliveira et al., 2012).

However, in the case of DFNSP, which is a pluralist organization that is composed of different police forces and government departments, it should be easier to deal with the security issues supported by behavioral theory.

Taking the studies of Deichmann and Stam (2015) as a starting point based on behavioral theory, the organization has as a decision system in which each person participates, rationally and consciously, trying to choose the "best" alternative. Corroborating this line of thought, the study authors, such as Soares (2003), Schmidt (1995), and Ensslin et al. (2001) point out the consolidation of one generic rational decision-making process, articulated in four stages: (i) decision to decide; (ii) definition of deciding; (iii) alternative formulation; and (iv) choice of the most suitable alternatives.

This generic decision-making process model can also be found in Military Police Organizations in Brazil, as can be observed in the decision-making process stages taken by the commanders, chiefs and directors. Those decisions are aligned with the process designed by Holten and Brenner (2015), which comprises five tasks: (i) problem identification; (ii) problem analysis; (iii) alternative formulation; (iv) alternative analysis; and (v) alternative selection. The approach advocated by the mentioned authors characterized the decision-making process as aligned to a rationalist paradigm.

Rational decision-makers have a similar knowledge level about a particular problem. It is the same reasoning logically, seeing the same information and all pursuing the same rational goals (Ensslin et al., 2001). However, according to Roy (1996), decisions are rarely taken by single individuals, even if there is only one responsible for the results. Decisions are products of different interactions between individuals' preferences and influence groups. This reality shows that each actor involved in the decision-making process has a value set that characterizes their interests in the decisions that are being built (Ensslin et al., 2001). This approach is characterized by Roy (1996) as part of a constructivist paradigm.

Ensslin et al. (2001), took bases on two specific approaches founded on the studies of Roy (1996), the first that is related to the rationalist paradigm, consolidated the knowledge areas linked to traditional operational research; and the second is related to constructive paradigm, where they are recognized as: (i) the uniqueness about the context and its actors; (li) the knowledge limits of the decision maker; (lii) social entity; (Iv) participation with recursive learning; (V) the principles of measurement; and (vi) the legitimacy and validation. As a result, Ensslin et al. (2010) highlight that the methodology "Multicriteria Decision Support" was incorporated into the " $\mathrm{C}$ " (Constructivist), becoming Multicriteria Decision Support - Constructivist (MCDA-C).

The MCDA-C method designed for the achievement of the decision support activity is developed in three phases: (i) structuring phase; (ii) evaluation phase; and (iii) recommendation phase. Figure 1 highlights how these phases and their steps are executed.

The structuring phase includes the following steps: (i) "soft" approach to structuring; (ii) family of viewpoints; (iii) Construction of descriptors.

The evaluation phase includes the following steps: (a) analysis of independence; (b) transformation of the descriptors in value functions; (c) determination of compensation rates; and (d) diagnosis of the current situation (status quo).

The Recommendation Phase includes the following steps: sensitivity analysis and recommendation's elaboration.

Based on the concepts presented, in order to develop the strategic planning that contemplates the Perimeter Security 
and the Patrimonial Security Plan for the 2016 Olympics, we developed a systematic supported by the scientific method presented in the sequence.

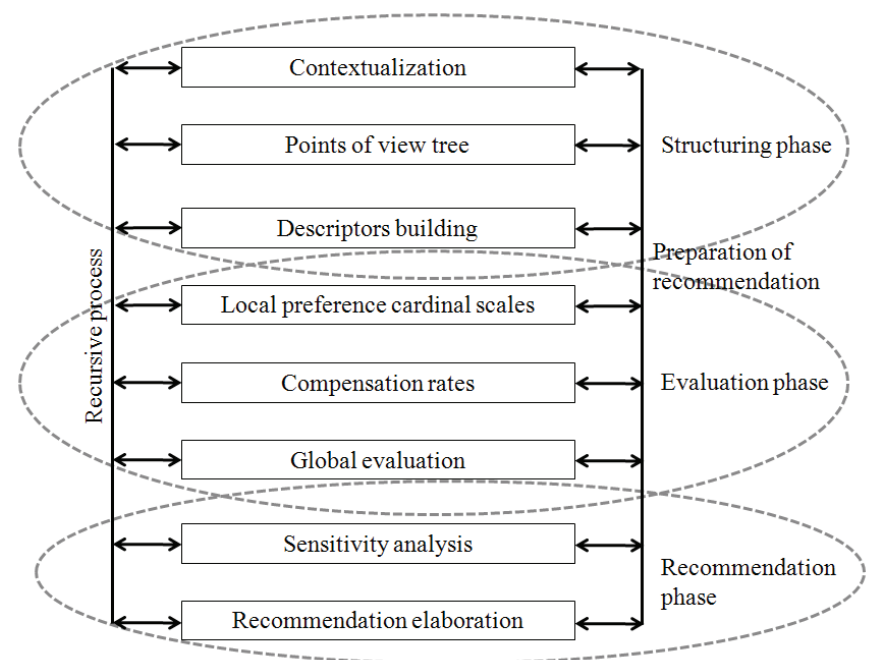

Figure 1. Phases of the MCDA-C Source: adapted from Moraes et al. (2010).

\section{METHODOLOGY}

Based on the presented issue we have established the combination of different methods resulting in the following steps in a systematic approach:

- Mission deployment (Daily meetings, based on the Scrum framework and MCDA-C methodology [structuring phase], in order to share knowledge and achieve the commitment of stakeholders in fulfilling the mission) is defined in detail (Meeting with $50 \%$ of GTRio1 to share what had been done so far and to contribute to the details of the task, and all the other General Managers, commanders, managers and others responsible for any activity performed in the National Force [Daily Scrum meeting technique]);

- Prioritize goals (starting from strategic goals in the direction of operational objectives to be achieved by each of the teams through their leaders, using the MCDA-C methodology [evaluation phase]);

- Identify Threats, Opportunities, Weaknesses, Strengths (Using the SWOT matrix);

1 GTRio - Rio Work Group. The group is composed of major staff members from DFNSP involved directly with the Olympics Games security.
- Define the production process and support, as well as the project layout, the organization chart and the professionals' allocation matrix (Delphi technique and MCDA-C methodology [recommendation phase]);

- Develop the final strategic planning report.

\section{METHODOLOGY APPLICATION AND PLAN CONSTRUCTION}

The initial planning followed according to the proposed methodology, we made daily meetings using the brainstorming technique, aiming to define the "mission", also share knowledge and establish the commitment of the stakeholders regarding the mission objectives achievement. As a result, we delivered a document containing the mission, roles, and responsibilities.

In the sequence, following the scrum daily meetings technique, we made the mission deployment, which started on October 15th, 2016 and ended on December 20th, 2015. Those meetings occurred at Rio de Janeiro with at least fifty percent of the working group (GTRio). GTRio is a group that comprises all the agencies engaged in security and defense of the Rio 2016 Olympic Games. As a result, all the requirements needed to develop the strategic resource plan for the Patrimonial and Perimeter Security of the 2016 Olympics Facilities were detailed.

To prioritize the goals, a subset of the Multicriteria Methodology Decision Support - Constructivist (MCDA - C), the structuring phase of MCDA-C, used to developed a "decision tree" was utilized. We utilized a top-down approach to hierarchize the strategic goals until we reached the operational tasks, which must be achieved by each of the security teams. One important information to highlight is that all the team leaders participated in this process. To check the results, a bottom-up approach was conducted.

This project started seeking forms of a method to generate and manage services from the different institutions participating on the Olympic Games Security that could represent the DFNSP results as a whole, taking into consideration the group of deciders' mind set on the top of command chain. Works as Gorman et al. (2008) presented help on our understanding of this field of knowledge boundaries. This outgoing resulted on the use of MDCA-C (Constructivist Decision Support Multicriteria Methodology) that allowed the creation of performance indicators and a management processes based on perfecting actions in continuous evaluation cycles.

To incorporate these new processes into the DFNSP routine, it is important to highlight the need for automation of 
the built model, making it a real-time updated management instrument that permits to quickly verify the performance variations, positive and negative, at all the organizational levels, being, thus, an effective supporting tool for the decision process.

\subsection{Results based on a Constructivist Decision Support}

After having the tasks listed, the overview demands related to the safety of the 2016 Olympics Games to be held in Rio de Janeiro were obtained. Therefore, we organized the task in two big groups (Operations and Resources), as can be seen in figure 2.

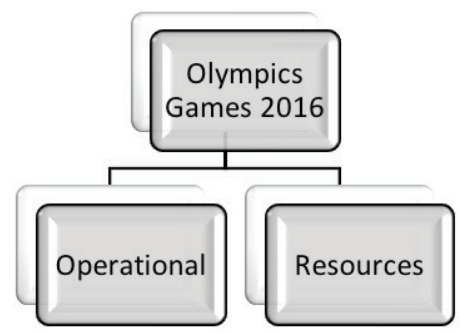

Figure 2. Overview of security operations Source - Authors (2017)

Applying the structuring phase of the MCDA-C on the Operational Group, as the following result was obtained: the descriptors represented the Elementary Viewpoints (EVPs), becoming the basis for the early reviews of the structured objectives, as it can be seen in figure 3 .

The process of hierarchizing the Elementary Viewpoints was followed until the operational objectives could be matched. This means that a person or team could be assigned to a task and this task could be measured. Besides the results of organizing the tasks in a systematic way, the process additionally generated knowledge to the decision makers and also to the whole team, bringing a holistic perception of the tasks and needs involved. Continuing to the process of hierarchizing, the MCDA-C structuring phase is used on the Resources Group. We dismember the hierarchy until we can achieve the tasks and their owners, as shown in figure 4.

In the sequence, the following step of MCDA-C, the evaluation phase, was followed; and the Key performance indicators (KPIs) were defined, in order to be able to follow the work progress.

Once the tasks and KPIs were performed, Threats, Opportunities, Weaknesses, Strengths, were identified and a SWOT matrix was developed. This matrix has assisted us in understanding the environment of the Olympics games. The members of the National Force were also allowed to see the possible scenarios, which were very instructive, to stablish the resources dimensioning, qualification and training needs, as well the control of operations and resources' distribution.

In order to define the production process and support, as well as the project lay-out, the organization chart, and the professionals' allocation matrix, the Delphi technic with the members of the "General Staff" was used, as it is an agency composed of officers and other personnel (information, study, design and planning) for supporting military command decisions, to validate and scrutinize the value hierarchical tree. It is worthy emphasizing that, in the end, the members of the Force knew what they had to do, what their responsibility was, and the impact of their work on the final result.

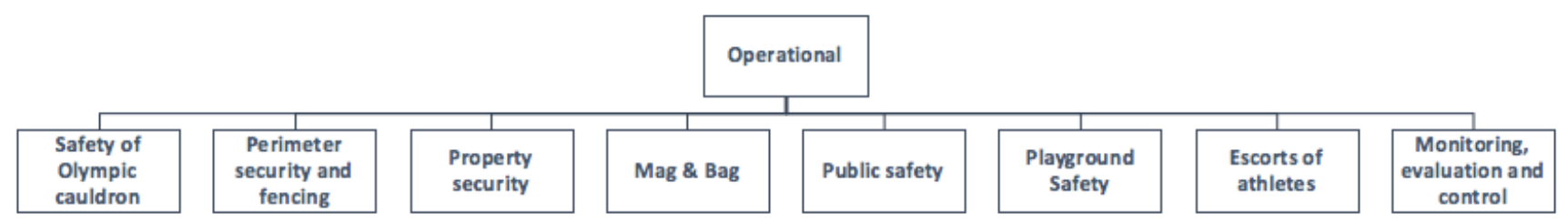

Figure 3. Detailed Operational PVE.

Source: Authors (2017)

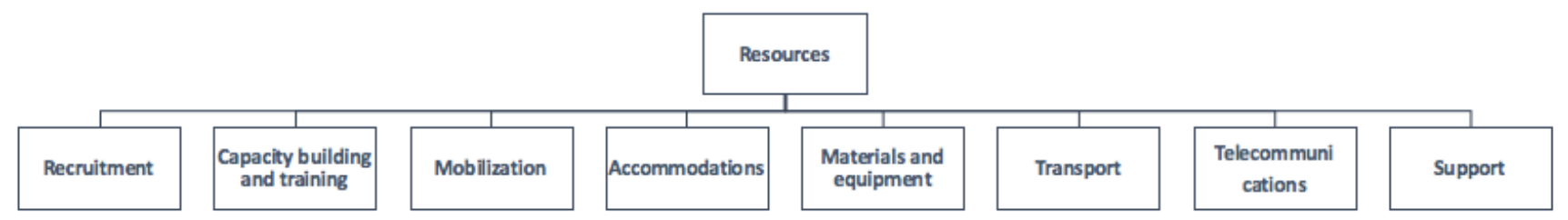

Figure 4. Unfolded PVEs Resources

Source: Authors (2017) 
Throughout the whole process, documents that have allowed generating the planning memory were prepared. With these documents, it is possible to disseminate what was made, as well as the objectives and tasks for those who have not been in the meetings.

In the last step, the final strategic planning report that comprises the General Operations Policy, General Operating
Support Policy, Tactics Plans and Operational Plans was developed. Figure 5 elucidates the document types, organizational level, and the owner.

In order to elaborate and evaluate internally the plans, and also to establish checkpoints, the agenda presented in table 1 were developed and followed.

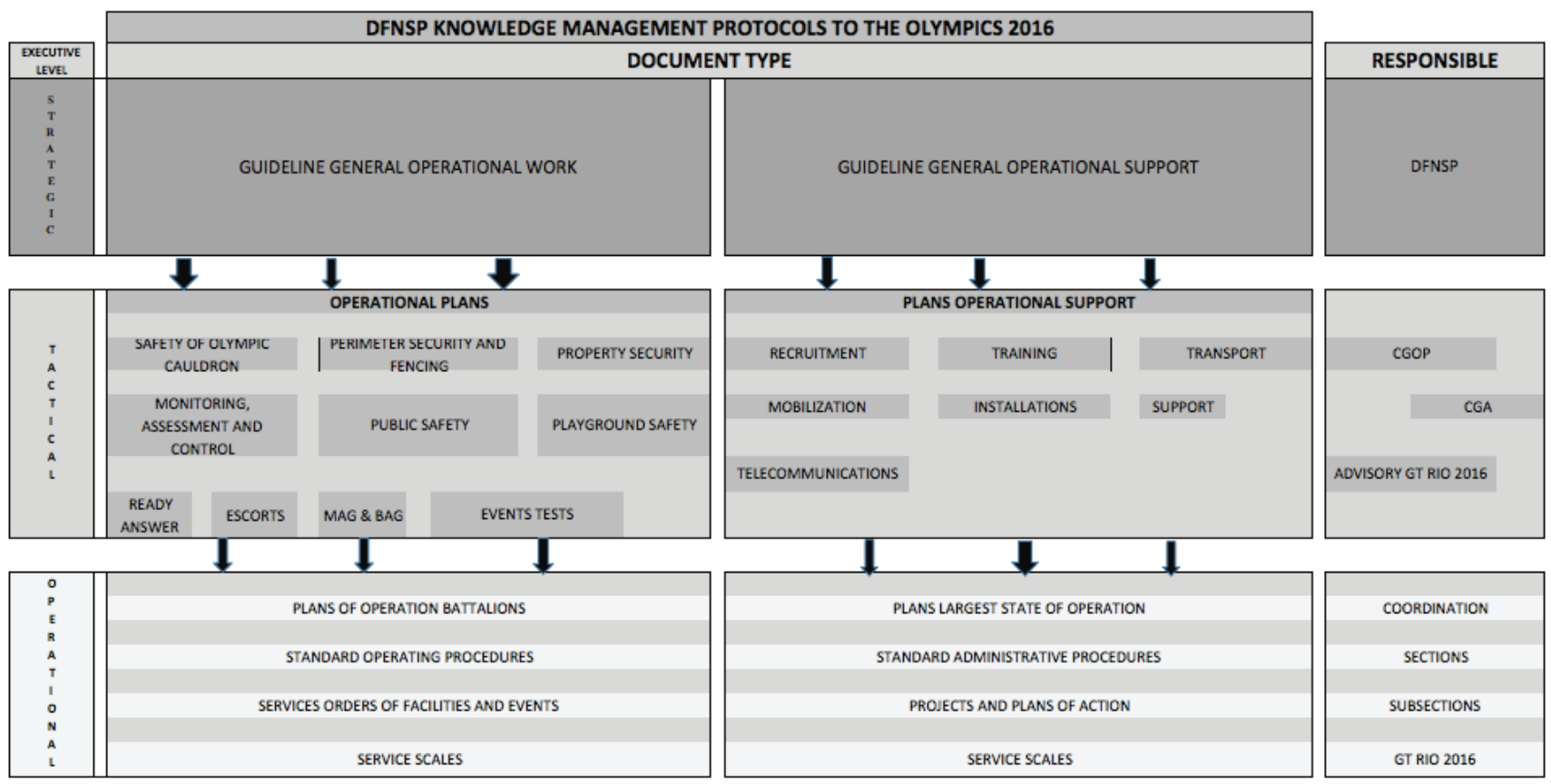

Figure 5. Documents produced to standardize the work of the National Public Security Force in 2016 Olympics Source: Authors (2017)

Table 1. Development schedule and delivery of the planning documents of the Olympics Games

\begin{tabular}{|c|c|c|}
\hline No & ACTIVITY & DEADLINE \\
\hline 1 & Operational plans tactical employment & December 14th 2015 \\
\hline 2 & Plans operational support tactical & December 21th 2015 \\
\hline 3 & Standart operating plans & December 21th 2015 \\
\hline 4 & Standart administrative plans & December 21th 2015 \\
\hline 5 & Review of POP and PAP for consultations collegiate & December 30th 2015 \\
\hline 6 & Correction of tactical plans responsible & December 30th 2015 \\
\hline 7 & Correction of SOP and PAP responsible & January 05th 2016 \\
\hline 8 & Submission of plans employment tactical operations and SOP & January 12th 2016 \\
\hline 9 & Submission of plans support tactical operations and SOP & January 14th 2016 \\
\hline 10 & Rertact & \\
\hline
\end{tabular}


After the games, advantage could be taken of the plan execution in action, and some operational perceptions results are presented.

\section{OPERATIONAL REFLECTIONS PAST THE OLYMPIC GAMES}

Strategically, the operations bases were held in four different places, called Olympic Regions, located in Barra, Copacabana, Deodoro, and Maracanã, (City of Rio de Janeiro). In these four areas, all security activities had summarized reports about all the security operations, positive aspects, the opportunity for improvement and lessons learned. Some aspects can be highlighted concerning the strategic planning:

\section{Positive aspects}

1. Coordination of all Rio 2016 Committee functional areas, among themselves and between the security of the Carioca Arena National Force;

2. Various agencies that composed the security team integration. The good relationship of cooperation between the Security Institutions and Rio 2016;

3. Punctuality in the troop's displacement to the events, ensuring the inspection of events and gate opening accomplishment at the scheduled time;

4. Participation in meetings of job planning together with Rio 2016 Committee;

5. All involved agencies improved the knowledge of planning;

6. Planning Team (Collegiate Advice) presence and approximated participation in the follow-up of each Region activities;

7. Integration between the various functional areas;

8. Harmony and good coexistence among all in the installation;

9. Sensitivity and resolution of the DFNSP coordination team to the reported situation;

10. Integrated Plans, Well-defined Operational Policies, Standard Operational Procedures;

\section{Opportunities for improvement}

1. Empowering a troop section in other languages;

2. Need for a previous meeting with volunteers and event employees to clarify the National Force responsibilities within the facility;

3. Training and instruction to drivers of private bus companies, who were sometimes unaware of the commuting routes to the facilities, as well as the appropriate accesses at the venue;

4. A better way to train mag $\&$ bag operators;

5. Disclosure of BEO (Special Operations Battalion) scales with a longer notice ( $48 \mathrm{~h}$ before) and availability in the DFNSP Intranet system, allowing better planning both by the officers who commanded the staff and the coordinators;

6. Delay in the functioning and attendance of all institutions in the Integrated Facilities Security Centers;

7. Sudden change in the scope of operation of the Mag $\&$ Bag on the eve of the competition made adaptation difficult and impaired the safety of facilities;

8. Absence of Mag \& Bag equipment in all Copacabana facilities;

\section{Lessons Learned}

1. The importance of planning, for the various security forces integration;

2. A good qualification of the personnel involved tends to improve planning;

3. Planning the plot should be flexible;

4. Planning done with versatility provides a good performance in the events.

5. Cooperation between security entities, which is fundamental to the process smooth running, one agency ended up complementing the limitations of the other;

6. The integrated work, as well as the Operational Planning developed by the DFNSP together with the Rio 2016 Committee, was of fundamental importance for obtaining situational awareness on the part of all the participants of the operation, which allowed the 
delivery of safety, pleasant to the customers of the Olympics Games Rio 2016.

The DFNSP performance in the Rio 2016 Games has effectively demonstrated the Brazilian public security forces quality that, even in the face of unstable scenarios for the facilities' security, demonstrated the quality and efficiency of the use of the strategic plan and available means.

\section{RESULTS AND FINAL THOUGHTS}

Highlight should be given to the complexity of a mega event such as the Olympics Games, for it possesses many faces and dimensions, from the decision moment until the moment in which the world watches the best athletes of each sport facing each other in healthy sporting competition. At this time, no external interference can be shinier than the sporting clash. Therefore, to receive the crowds that will flock to the venue, there are several demands, for instance: road, tourism, and urban infrastructures, among others, should be taken into consideration and be delivered on time for the event.

In this context, it should be highlighted the importance of site security of the competition adjacencies, of the playing field perimeter and of the public attending the event. As an anonymous and unseen action, the security system should also act to anticipate the possibility of conflict with ease and efficiency, as well as it must act to preserve the order.

This task was delegated to the National Public Security Force. Whose mission was oriented to perimeter security, fence and access to competition, training and surrounding areas? The complexity of the activity extended from the synergetic integration with other defense and law enforcement agencies.

In order to accomplish this mission, it was necessary to conduct a detailed logistical and operational planning, taking into consideration its high-risk degree and the need for arms, equipment, communication, transportation, recruitment, training and troops accommodation that could reach ten thousand men and women, from different places and throughout the country. This expectation was threatened by a historical experience of precarious planning and consequent improvisation performances in previous events.

Following the methodology proposed in this study proved to be of great value, once it helped identifying the points of views of the National Force performance, ranking them in a structured value hierarchical tree that grew through time, evolving the strategic level PVEs for operating. Moreover, it shared the mission, tasks, and activities with all the corporation administrative dimensions. In addition, this planning stage allowed spreading among all corporate levels the val- ues and experience of the Administrative Force Directors, who worked in the construction process of the hierarchical tree values as a decision maker.

In knowing the main Elementary Points of View that the operation demanded, it was possible to draft the General Guidelines, the Tactical Plans, and the Standards Procedures. These documents, in addition to making the bond of PVEs with the rules and laws, made explicit each one of them in a peculiar language so that the actions would be operationalized. They made perennial the reasons and objectives of each PVE.

With the planning result, through the documents, the staffs that had participated in meetings for drafting the value hierarchical tree or not, could have access to it and to the way it was prepared. This allowed them to have a better understanding, not only of the process, but also of the role and responsibility of each of the involved. It is emphasized that it was developed based on the documents, a training booklet of new recruits for the event, and a guide for the managers.

It is noticed and should be emphasized that mega events security planning demands the intervention of multiple methodology and planning and management tools. All of them need to interact in order to perform the complex task of planning such a complex mission. And the steps indicated by the systematic approach described in the methodology of this work are one possible solution to this issue.

\section{REFERENCES}

Araujo, L. C. (2010), Organização, sistemas e métodos e as tecnologias de gestão organizacional, 3rd ed., Vol. 2., Atlas, São Paulo.

Bienenstein, G. et al. (2011), O jogo continua: megaeventos esportivos e cidades, EdUerj; Faperj, Rio de Janeiro.

Cardoso, B. V. (2010), Todos os olhos: videovigilâncias, videovoyeurismos e (re) produção imagética na tecnologia digital, Tese de Doutorado em Antropologia Cultural, Instituto de Filosofia e Ciências Sociais, Universidade Federal do Rio de Janeiro, Rio de Janeiro.

Certo, S. C.; Peter, P. J. (1993), Administração estratégica: planejamento e implantação estratégica. Tradução: Flávio Deni Steffen, Pearson Education do Brasil, São Paulo.

Cunha, A. H. et al. (2015), "The MCDA-C As a Decision Support Instrument in Police Organizations", Business Management Review (BMR), Vol. 4, pp. 629-53.

Deichmann, D.; Stam, D. (2015), "Leveraging transformational and transactional leadership to cultivate the generation of organization-focused ideas", The Leadership Quarterly, Vol. 26, No. 2. 
Duarte, F.; Firmino, R. (2010), “Espaço, visibilidade e tecnologias: (re) caracterizando a experiência urbana", in: Bruno, F. et al. (Ed.), Vigilância e visibilidade: espaço, tecnologia e identificação, Sulina, Porto Alegre, pp. 94-112.

Ensslin, L. et al. (2010), “Avaliação do desempenho de empresas terceirizadas com o uso da metodologia multicritério de apoio à decisão-construtivista", Pesquisa Operacional, Vol. 30, No. 1, pp. 125-52. ISSN 0101-7438.

Ensslin, L. et al. (2010), ProKnow-C, Knowledge Development Process - Constructivist: processo técnico com patente de registro pendente junto ao INPI, Brasil.

Ensslin, L. et al. (2010), ProKnow-C, Knowledge Development Process- Constructivist. Processo técnico com patente de registro pendente junto ao INPI, Brasil.

Ensslin, L. et al. (2001), Apoio à decisão: metodologia para estruturação de problemas e avaliação multicirtério de alternativas, Insular, Florianópolis. ISBN 85-7474-093-4.

Giulianotti, R.; Klauser, F. (2009), "Security governance and sport mega- events: Toward an interdisciplinary research agenda", Journal of Sport and Social Issues, Vol. 34, pp. 49-61.

Holten, A.; Brenner, S. O. (2015), "Leadership style and the process of organizational change", Leadership \& Organization Development Journal, Vol. 36, No. 1.
Oliveira, D. P. R. (2010), Planejamento estratégico, Atlas, São Paulo.

Oliveira, L. R. et al. (2012), "Sustentabilidade: da evolução dos conceitos à implementação como estratégia nas organizações", Produção, Vol.22, No.1, pp. 70-82.

Qazi, A. et al. (2016), "Project complexity and risk management (ProCRiM): Towards modelling project complexity driven risk paths in construction projects", International Journal of Project Management, Vol. 34, pp. 1183-98.

Roy, B. (1996), Multicriteria methodology for decision aiding, Klumer Academic Publishers, Dordrecht.

Schmidt, A. M. A. (1995), Processo de apoio à tomada de decisão - Abordagens: AHP e MACBETH, Dissertation, Universidade Federal de Santa Catarina, Florianópolis, available at: www.eps.ufsc.br/disserta/engait95.html (acesso em: 06 maio 2016).

Soares, S. R. (2003), Análise multicritério com instrumento de Gestão Ambiental, Dissertation, Universidade Federal de Santa Catarina, Florianópolis, SC.

Tavares, M. C. (2008), Gestão Estratégica, 2nd ed., Atlas, São Paulo.

Received: 12 Jan 2018

Approved: 08 May 2018

DOI: 10.14488/BJOPM.2018.v15.n2.a10

How to cite: Cunha, A. H., Marcineiro, N., Ferenhof, H. A. et al. (2018), "The Impact of Strategic Planning on Institutional Integration Toward Patrimonial and Perimeter Security Planning of the 2016 Olympics Games", Brazilian Journal of Operations \& Production Management, Vol. 15, No. 2, pp. 285-293, available from: https:// bjopm.emnuvens.com.br/bjopm/article/view/439 (access year month day). 